\title{
Community-Engagement Strategies of the Developmental Disabilities Practice-based Research Network (DD-PBRN)
}

\author{
Carl V. Tyler, MD, MSc, and James J. Werner, PhD, MSSA
}

There is often a rich but untold history of events that occur and relationships that form before a practice-based research network (PBRN) is launched. This is particularly the case in PBRNs that are community based and comprise partnerships outside of the health care system. In this article we summarize an organizational "prenatal history" before the birth of a PBRN devoted to people with developmental disabilities. Using a case study approach, this article describes the historic events that preceded and fostered the evolution of this PBRN and contrasts how the processes leading to the creation of this multistakeholder, community-based PBRN differ from those of typical academic/clinical practice PBRNs. We propose potential advantages and complexities inherent to this newest iteration of PBRNs. ( $\mathrm{J}$ Am Board Fam Med 2014;27:831-838.)

Keywords: Community-Based Participatory Research; Developmental Disabilities; Populations, Underserved; Practice-based Research

Since their beginnings in the 1970s, practice-based research networks (PBRNs) in the United States often have been formed by state and national academies of family medicine and by medical school and residency primary care faculty in collaboration with

This article was externally peer reviewed.

Submitted 16 January 2014; revised 6 August 2014; accepted 11 August 2014.

From the Cleveland Clinic Lerner College of Medicine (CVT) and the Department of Family Medicine and Community Health and Mandel School of Applied Social Sciences (JJW), Case Western Reserve University, Cleveland; the Fairview Hospital/Cleveland Clinic Family Medicine Residency, Cleveland (CVT); and the Practice-Based Research Network Shared Resource, Cleveland Clinical and Translational Science Collaborative, Cleveland (JJW).

Funding: This publication was made possible through the PBRN Shared Resource of the Clinical and Translational Science Collaborative of Cleveland; grant UL1TR000439 from the National Center for Advancing Translational Sciences (NCATS) component of the National Institutes of Health (NIH) and NIH Roadmap for Medical Research; and the Case Comprehensive Cancer Center Support Grant 2P30CA043703-23 of the National Cancer Institute (NCI), NIH.

Disclaimer: The contents of this article are solely the responsibility of the authors and do not necessarily represent the official views of the NIH.

Conflict of interest: none declared.

Corresponding author: Carl V. Tyler, MD, MSc, Fairview Hospital/Cleveland Clinic Family Medicine Residency, Center for Family Medicine, 18200 Lorain Ave, Cleveland, OH 44111 (E-mail: catyle@ccf.org). community practices at local, regional, and national levels. ${ }^{1}$ This article describes an alternative pathway to PBRN development in which the network is formed by multiple stakeholder groups who are invested in the care of a target patient population, including nonclinician stakeholders involved in service, advocacy, and education. The pathway described here may serve as a template for the development of community-engaged PBRNs.

\section{A Historic Context to Health Care and People with Developmental Disabilities}

Developmental disabilities (DDs) are defined by federal law as severe chronic disabilities manifesting before age 22 due to a physical and/or mental impairment and resulting in "substantial functional limitations in 3 or more of the following areas of life activity: (1) self-care; (2) receptive and expressive language; (3) learning; (4) mobility; (5) selfdirection; (6) capacity for independent living; and (7) economic self -sufficiency." 2 Population estimates for DDs in the United States vary between $1.5 \%$ and $2.5 \%{ }^{3}$ Most people with DDs live in the community, most commonly with family members, with additional support from educational, vocational, and social service programs. ${ }^{4}$ 
An emerging literature base is documenting widespread disparities in the health and health care of people with DDs, including both preventive and chronic disease care. ${ }^{5-7}$ While some individuals with DDs have complex specialty health care needs that assume much of their health care activity, all are in need of primary care. Unfortunately, many primary care physicians report little formal training in the care of this population. ${ }^{8-10}$

Critical historic events involving the medical community, as well as prevailing societal attitudes, feed a persisting distrust of the health care system by people in the DD community. In the past, physicians routinely advised families to institutionalize children with DDs to avoid "harming" their other children; inaccurate and pessimistic prognoses regarding the health, function, and life expectancy of children with DD were typical. ${ }^{11}$ Unauthorized research conducted on people with DDs ranged from experimental exposure to radioactive substances in food to purposeful infection with viral hepatitis. ${ }^{12-16}$ Even now, health care professionals counseling expectant parents about prenatal diagnoses of Down syndrome and other genetic conditions tend to present biased views regarding the typical functional status and "quality of life" of children with these conditions, with the assumption that all parents would elect to terminate the pregnancy given the "proper" information. ${ }^{17-19}$

Health care providers often are unfamiliar with the complexities of their local DD service system, which may or may not include a widely variable and ever-changing range of health, vocational, educational, and residential services provided by county boards of DD, profit and not-for-profit residential service providers, and community-based agencies. Not surprisingly, health care providers make clinically unsupported assumptions about the extent of training and intensity of supports their medically fragile patients with DD receive from community service providers. ${ }^{20,21}$ Without a proper understanding of the DD service system, even well-intentioned, carefully crafted health care plans are unlikely to yield expected results.

\section{Evolution of the DD-PBRN}

The DD-PBRN is a multistakeholder, communitybased PBRN established in 2013 with the support of the PBRN Shared Resource at Case Western Reserve University through the National Institutes of Health-funded Cleveland Clinical and Translational Science Collaborative (Figure 1). The mission of the DD-PBRN is to "improve the health and health care of persons with developmental disabilities throughout the lifespan through inquiry and action involving collaborations among the health care, service and disabilities communities."

Acknowledging this overall historic context, the "prenatal history" of the DD-PBRN can be conceptualized in 3 stepwise phases: (1) affiliation through shared service; (2) emerging mission of advocacy and clinical education; and, finally, (3) expanding the mission to health system change and research. The organizational history and framework presented below were derived from reviews of meeting notes, academic presentations and products, and E-mail communications related to collaborative activities. Drafts of this organizational history were reviewed by participants to ensure their accuracy. A timeline of collaborative activities leading to the establishment of the DD-PBRN are summarized in Table 1. This timeline illustrates the consistent structural core of participating membership, representing the patient, advocacy, service, and health care communities throughout the entire prenatal history of the DD-PBRN.

\section{Phase 1: Affiliation Through Shared Service}

Individuals (and their affiliate organizations) who would ultimately establish the DD-PBRN first became acquainted with each other through service provision to shared clients/patients residing within

\section{Figure 1. Stakeholders represented in the Developmental Disabilities (DD) Practice-Based Research Network.}

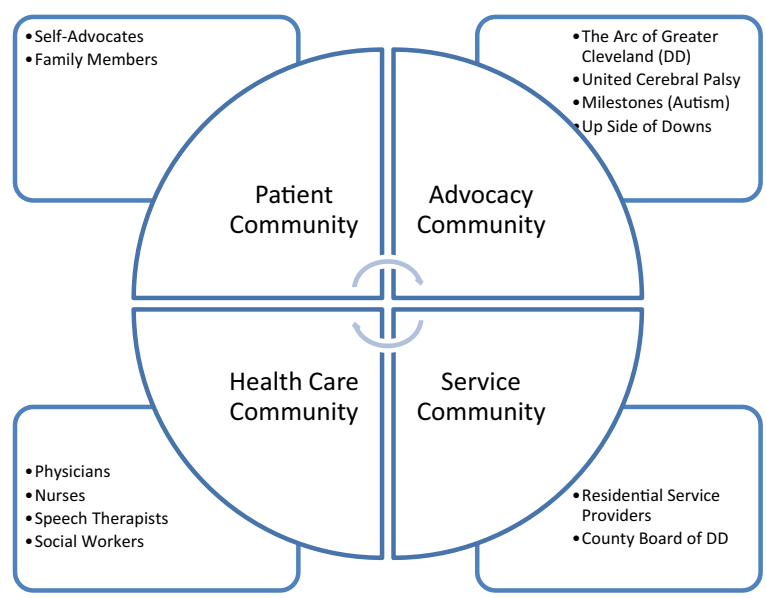


Table 1. Timeline of Collaborative Activities and Participants, Organized by Representative Stakeholder Groups

\begin{tabular}{|c|c|c|c|}
\hline $\begin{array}{l}\text { Collaboration } \\
\text { (Years) }\end{array}$ & $\begin{array}{l}\text { Training Grant } \\
(2009-2011)\end{array}$ & $\begin{array}{l}\text { Learning Collaborative } \\
\qquad(2012-2013)\end{array}$ & $\begin{array}{l}\text { DD-PBRN } \\
\text { (2013 to present) }\end{array}$ \\
\hline \multicolumn{4}{|c|}{ Stakeholder Group } \\
\hline Patient & $\begin{array}{l}\text { Self-advocates } \\
\text { Family members }\end{array}$ & $\begin{array}{l}\text { Self-advocates } \\
\text { Family members }\end{array}$ & $\begin{array}{l}\text { Self-advocates } \\
\text { Family members }\end{array}$ \\
\hline Advocacy & $\begin{array}{l}\text { The Arc of Greater Cleveland } \\
\text { Upside of Downs }\end{array}$ & $\begin{array}{l}\text { The Arc of Greater Cleveland } \\
\text { Upside of Downs } \\
\text { United Cerebral Palsy }\end{array}$ & $\begin{array}{l}\text { The Arc of Greater Cleveland } \\
\text { Upside of Downs } \\
\text { United Cerebral Palsy } \\
\text { Milestones (Autism) }\end{array}$ \\
\hline Service & $\begin{array}{l}\text { Residential service providers } \\
\text { (Welcome House, Help } \\
\text { Foundation) } \\
\text { Disabilities professionals } \\
\text { Cuyahoga County board of DD }\end{array}$ & $\begin{array}{l}\text { Residential service providers } \\
\text { (Welcome House, Help } \\
\text { Foundation) } \\
\text { Disabilities professionals } \\
\text { Cuyahoga County board of DD }\end{array}$ & $\begin{array}{l}\text { Residential service providers } \\
\text { (Welcome House, Help } \\
\text { Foundation, Koinonia, } \\
\text { Mentor Network, ViaQuest) } \\
\text { Disabilities professionals } \\
\text { Cuyahoga County board of DD }\end{array}$ \\
\hline Health care & $\begin{array}{l}\text { Nurses } \\
\text { Family physicians } \\
\text { Residency faculty } \\
\text { Medical school faculty }\end{array}$ & $\begin{array}{l}\text { Nurses } \\
\text { Family physicians } \\
\text { Internists } \\
\text { Pediatrician } \\
\text { Speech therapist }\end{array}$ & $\begin{array}{l}\text { Nurses } \\
\text { Family physicians } \\
\text { Internists } \\
\text { Pediatrician } \\
\text { Speech therapist } \\
\text { Social workers }\end{array}$ \\
\hline
\end{tabular}

DD, developmental disabilities; PBRN, practice-based research network.

a metropolitan area of northeastern Ohio; the area's total population of nearly 2.1 million residents includes an estimated 30,000 individuals with DD, of whom approximately 13,000 are served by the Cuyahoga County Board of Developmental Disabilities. Over the course of years, members of the disabilities and service communities slowly developed trusting relationships with a small cadre of physicians who demonstrated expertise and commitment to this population. Mutual respect and understanding further developed between members of these 3 communities through collaborative management of complex client situations in which extensive communication and problem-solving between groups were required. Examples of client scenarios requiring high-intensity communication and collaboration included sexual abuse by a neighborhood predator, poor diabetes self-care jeopardizing community residence, recurrent hospitalizations for heart failure, and behavioral health issues.

\section{Phase 2: An Emerging Mission of Advocacy and Clinical Education}

A pivotal turning point that shaped the organizational vision for future PBRN members occurred in the context of a Family Medicine Education Consortium conference held locally in 2000. A family medicine residency faculty with a clinical focus in DDs (and the future director of the DD-PBRN) organized a full-day preconference dedicated to primary care and DDs. Most of the presentations were given by invited members of the disabilities and service communities rather than physicians. The presenters included self-advocates, parents, representatives of advocacy organizations, and nonphysician disabilities professionals. In addition to the presenters, the audience comprised approximately 25 family medicine residency faculty, family medicine resident physicians, and medical students from the northeastern United States. For the next decade, the Family Medicine Education Consortium maintained this precedent by hosting an annual full-day preconference devoted to primary care and DDs, with continued participation by members of the disabilities and service communities. Consequently, self-advocates, family members, and service providers began to see a role for themselves as vitally important educators of physicians. Many became involved in ongoing training of resident physicians at their local family medicine residency training programs. They recognized that the education of health professionals was a concrete means of ensuring and advocating for better health care.

In 2008 the Ohio Developmental Disabilities Council called for training grant proposals aiming at improving the primary care of adults with DDS. In response, the future DD-PBRN director gathered representatives of 2 residential service provider organizations (Help Foundation and Wel- 
come House) and a local chapter of a national DD advocacy organization (The Arc of Greater Cleveland) to craft a submission. Previously established relationships between these stakeholder communities allowed the grant proposal to be written within 6 weeks. This group was awarded a 3 -year training grant that provided the future PBRN members an opportunity to create enduring training materials to improve the health and health care of adults with DDs. ${ }^{22}$ Working as a united group, the multiple stakeholders wrote the content for a 3-module training DVD and served as the actors for the clinical vignettes embedded within it. Each module addressed a different audience: the self-advocate (an individual with a DD), the direct support professional or family member, and the health care team. The collaborators also wrote a training curriculum for direct support professionals providing care for aging adults with DDs. Finally, they helped create and pilot test a behaviorally anchored videotape review instrument to allow physicians in training to improve their communication skills with people with DDs through structured review of videotaped "live" clinical encounters. These products of the training grant were disseminated by the grant participants to each of their affiliate stakeholder communities.

A shared mission of advocacy was further promoted by the invitation of physicians to serve on boards of advocacy organizations such as The Arc of Greater Cleveland.

\section{Phase 3: Expanding the Mission to Health System Change and Research}

The training DVD referenced above was premiered in a "red carpet" gala where participants in the training grant and additional invited members from the stakeholder communities viewed selected portions of the video. Invited guests included administrative officials from the Cleveland Clinic, the sponsoring health care institution. Following the successful completion of the training grant and the positive publicity surrounding it, the future PBRN director requested and received internal support from the Medicine Institute of the Cleveland Clinic to fund a year-long project called the Learning Collaborative in Developmental Medicine. Through this venue, the future PBRN collaborators met 1 half day every other month to examine the health care needs of specific subpopulations of people with DDs, for example, Down syndrome, autism, and cerebral palsy. Meet- ings included presentations by self-advocates and family members about their personal experiences of health care and the sharing of content knowledge through didactic lectures by collaborative members. Local health system-level data relevant to the specific population under discussion were made available through Explorys (Cleveland, $\mathrm{OH}$ ), an electronic health record analytic platform company affiliated with the Cleveland Clinic. Clinical resources embedded in the electronic health record were created to enhance care.

In 2013 the PBRN Shared Resource at Case Western Reserve University began supporting the Learning Collaborative's trajectory as a multifaceted, multistakeholder network. The network is now known as the DD-PBRN. It continues to include the core components of advocacy, clinical education, collaborative learning, and research.

Since its inception in 2013, the DD-PBRN has clarified its organizational mission and vision, hosted regular steering committee meetings, and submitted a grant proposal to the Patient-Centered Outcomes Research Institute. Once its local base is solidified, it plans to network with other disabilities, service, and health care communities throughout the nation.

\section{Reflections on the Organizational History of DD-PBRN}

\section{Community Engagement: A Matter of Sequencing}

As referenced in Figure 2, early generation PBRNs originally comprised primarily of academic-clinical partnerships, are increasingly, and rightfully, concerned with community engagement with people and organizations outside of the formal health care system. ${ }^{23}$ Typically, this often occurs organizationally at a stage long after the PBRN was originally established, and it is now maturing and clarifying its mission and focus. In contrast, as illustrated in the case of the DD-PBRN, community engagement occurred as the initial organizing process, linking the health care community with other relevant communities long before the vision of a research mission was even contemplated. We propose that individuals who are involved in a PBRN from its inception-and the stakeholder groups they represent-would have a greater sense of perceived insider status, psychological ownership, and organizational identification than people who are invited as newcomers at a later time. ${ }^{24}$ 
Figure 2. Comparing development of "first-generation" practice-based research networks (PBRNs) with that of the Developmental Disabilities PBRN.

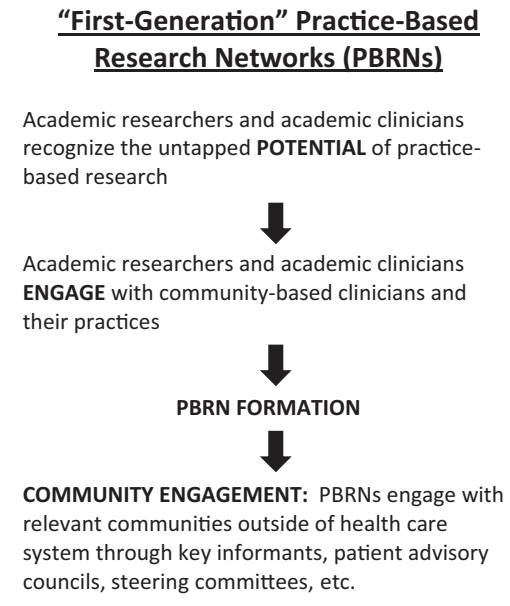

Developmental Disabilities (DD)-PBRN

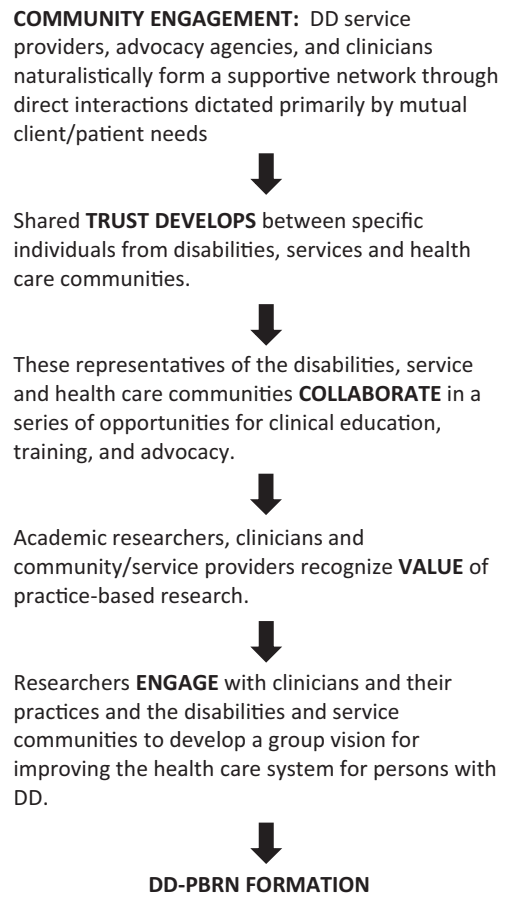

\section{The Role of Advocacy and Education}

While some PBRNs addressing health care disparities in underserved populations may become involved with wider advocacy issues, ${ }^{25-27}$ early generation PBRNs have tended to focus more strictly on research and the dissemination of specific findings. As illustrated by the DD-PBRN, advocacy was one of the core organizing principles for the network and will undoubtedly continue to be so. Community-based PBRNs such as the DD-PBRN are more likely to explicitly engage in advocacy as part of their core mission because they include advocates and advocacy organizations as core stakeholders. One of the challenges of this kind of network is balancing the demands of research with advocacy and other activities.

Similarly, community-based PBRNs, exemplified by LA Net, ${ }^{28-32}$ are more likely to engage in broader roles of clinical education and communitywide education as part of their core activities. As illustrated in the prenatal history of the DDPBRN, a shift in organizational dynamics occurred between organizational partners when members of the disabilities and service communities recognized their value as clinical educators to members of the health care system through their involvement as presenters at the Family Medicine Education Consortium annual meetings. The desperate need for basic health information related to DDs both within and outside of the health care community will make education an ongoing activity of the DD-PBRN.

\section{Flexibility Through Diversity}

The diversity of membership within the nascent DD-PBRN allows for more expansive projects with a broader reach than what would have been possible if only 1 of the 3 participating communities had been involved. Similarly, we anticipate that more funding opportunities will be available as different support streams generally available to one stakeholder group or another become available to the entire group through their collaborative relationships as part of the DD-PBRN.

Diverse membership also promotes flexibility in potential study designs. For example, to improve the health care of adults with Down syndrome, the DD-PBRN designed a study that intervenes through virtual consultations with the primary care physician; we are now designing a study that inter- 
Table 2. Characteristics of "First-Generation" Primary Care Practice-based Research Networks (PBRNs) Compared With the Developmental Disabilities (DD) PBRN

\begin{tabular}{|c|c|}
\hline "First Generation" Primary Care PBRNs ${ }^{38}$ & DD-PBRN \\
\hline $\begin{array}{l}\text { "PBRNs capture health care events that reflect the selection } \\
\text { and observer bias that characterize primary care in } \\
\text { community-based patient populations." }\end{array}$ & $\begin{array}{l}\text { The DD-PBRN intends to capture phenomena relevant to } \\
\text { primary health care of people with DD that may precede, } \\
\text { occur during, or occur subsequent to actual health care } \\
\text { events. Selection and observer biases vary according to } \\
\text { specific networks and participants. }\end{array}$ \\
\hline $\begin{array}{l}\text { "PBRNs provide access to the practice experience and care } \\
\text { provided by full-time primary care clinicians." }\end{array}$ & $\begin{array}{l}\text { The DD-PBRN intends to access the experience of } 3 \\
\text { stakeholder groups: primary care clinicians, their patients, } \\
\text { and other persons in the community who are relevant to } \\
\text { the primary health care of the persons with DD (ie, } \\
\text { representatives of the advocacy and service communities) }\end{array}$ \\
\hline $\begin{array}{l}\text { "PBRNs focus their activities on practice-relevant research } \\
\text { questions, apply appropriate, multi-method research } \\
\text { design, and generally avoid the tendency to permit } \\
\text { research methods to define the question." }\end{array}$ & $\begin{array}{l}\text { The DD-PBRN intends to focus its activities on the primary } \\
\text { health care of people with DD and applies appropriate } \\
\text { multimethod research designs that vary according to the } \\
\text { research questions proposed; studies vary in site, target } \\
\text { stakeholder group, and stakeholder perspectives. }\end{array}$ \\
\hline $\begin{array}{l}\text { "PBRNs strive for the systematic involvement of network } \\
\text { clinicians in defining the research questions, participating } \\
\text { in the study design, and interpreting study results." }\end{array}$ & $\begin{array}{l}\text { The DD-PBRN intends to strive for the systematic } \\
\text { involvement of primary care clinicians, people with DD, } \\
\text { and other stakeholders in the community who are relevant } \\
\text { to the primary health care of people with DD in defining } \\
\text { research questions, participating in the study design, and } \\
\text { interpreting study results. }\end{array}$ \\
\hline
\end{tabular}

venes through tailored resources provided to family members and residential service providers.

\section{Hybrids, Chimeras, or a New Species Altogether? The Community-Engaged PBRN}

There arises the question of whether to categorize the DD-PBRN as a PBRN at all; rather, is it an academic-community research partnership or some type of community-based research collaboration? Drawing on published literature articulating the core features of "first-generation" PBRNs, ${ }^{38}$ Table 2 describes how the DD-PBRN builds on but maintains fidelity to the core characteristics of a PBRN.

\section{Critical Resources}

The idea of a DD-PBRN slowly emerged following years of affiliation between constituent members. This emergent vision grew from a series of logical next steps, not by following a predetermined road map that was evident from the beginning. It developed in the context of a series of success experiences in which future PBRN members engaged in tasks beyond the scope of their usual daily work, for example, co-creating training and clinical resources and educating health professionals. A stable core of participants and partnering organizations enabled incremental group cohesion, fostered experiential knowledge, and stimulated awakening interest in health care improvement at the health system level. Leadership from the future PBRN director was required to identify, apply for, and coordinate these funded opportunities. The PBRN Shared Resource at Case Western Reserve University provided training to the future PBRN director through a 3 -year fellowship in practice-based research design and methodology. The PBRN Shared Resource also provided critical assistance with the transition from learning collaborative to PBRN by providing a PBRN coordinator, educating PBRN members about practice-based research, and providing technical assistance with its first study. The DD-PBRN coordinator is currently supported by the PBRN Shared Resource at Case Western Reserve University, whereas the PBRN director's effort is supported by his sponsoring health care institution, the Cleveland Clinic.

\section{Conclusion}

Recollection and reflection about events leading to the creation of both recently and long-established PBRNs may assist others in their own efforts to establish new PBRNs and may provide ideas for ways existing networks might evolve by forging unique partnerships within and outside of the health care system. The DD-PBRN exemplifies a new generation of community-oriented PBRNs, whose complex origins began through shared ser- 
vice affiliations and whose present missions include advocacy and education as well as research.

The authors thank Rick Rader MD, Director of Morton J. Kent Habilitation Center at Orange Grove for his assistance with supportive documentation regarding the history of medical experimentation on persons with developmental disabilities. The authors also gratefully acknowledge representatives of the following organizations in the genesis of the DD-PBRN: The Arc of Greater Cleveland, Case Western Reserve University, Cleveland Clinic, Cleveland Clinical and Translational Science Collaborative, Cuyahoga County Board of Developmental Disabilities, HELP Foundation, Northeast Ohio Medical University, Welcome House, United Cerebral Palsy of Greater Cleveland, The Mentor Network, Koinonia, Via Quest, and Up Side of Downs. The authors thank Jennifer Solivas-Maluyao, MD; Linda Council, MSN, RN; and Michelle Abraham, MSSA, LISW, for their thoughtful review of this manuscript and Kathy Gaughan, BA, for her secretarial assistance. Finally, the authors gratefully acknowledge the personal support and institutional funding for the Learning Collaborative in Developmental Medicine provided by David Longworth, MD, Medicine Institute Chair, Cleveland Clinic.

\section{References}

1. Green LA, Hickner J. A short history of primary care practice-based research networks: from concept to essential research laboratories. J Am Board Fam Med 2006;19:1-10.

2. Administration of Intellectual and Developmental Disabilities (AIDD). Developmental Disabilities Assistance and Bill of Rights Acts of 2000. Washington, DC: Administration for Community Living, US Department of Health and Human Services; 2000. Available from: http://www.acl.gov/Programs/AIDD/DDA_ BOR_ACT_2000/index.aspx. Accessed July 9, 2014.

3. Morstad D. How prevalent are intellectual and developmental disabilities in the United States? Watertown (WI): Bethesda Institute; 2012. Available from: http:// bethesdainstitute.org/document.doc?id=413. Accessed July 9, 2014.

4. Williamson HJ, Perkins EA. Family caregivers of adults with intellectual and developmental disabilities: outcomes associated with U.S. services and supports. Intellect Dev Disabil 2014;52:147-59.

5. Krahn GL, Fox MH. Health disparities of adults with intellectual disabilities: what do we know? What do we do? J Appl Res Intellect Disabil 2014;27:431-46.

6. Andresen EM, Peterson-Besse JJ, Krahn GL, Walsh ES, Horner-Johnson W, Iezzoni LI. Pap, mammography, and clinical breast examination screening among women with disabilities: a systematic review. Womens Health Issues 2013;23:e205-14.

7. Krahn GL, Hammond L, Turner A. A cascade of disparities: health and health care access for people with intellectual disabilities. Ment Retard Dev Disabil Res Rev 2006;12:70-82.

8. Tyler CV Jr, Snyder CW, Zyzanski SJ. Caring for adults with mental retardation: survey of family prac- tice residency program directors. Mental Retard 1999;37:347-52.

9. Wilkinson J, Dreyfus D, Cerreto M, Bokhour B. "Sometimes I feel overwhelmed": educational needs of family physicians caring for people with intellectual disability. Intellect Dev Disabil 2012;50:243-50.

10. Holder M, Waldman HB, Hood H. Preparing health professionals to provide care to individuals with disabilities. Int J Oral Sci 2009;1:66-71.

11. Pueschel SM, Murphy A. Assessment of counseling practices at the birth of a child with Down's syndrome. Am J Ment Defic 1976;81:325-30.

12. Bronner F, Harris RS, Maletskos CJ, Benda CE. Studies in calcium metabolism; the fate of intravenously injected radiocalcium in human beings. J Clin Invest 1956;35:78-88.

13. Rothman DJ. Were Tuskegee and Willowbrook "studies in nature?" Hastings Cent Rep 1982;12:5-7.

14. Ward R, Krugman S, Giles JP, Jacobs AM, Bodansky O. Infectious hepatitis: studies of its natural history and prevention. N Engl J Med 1958;258:407-16.

15. Krugman S, Ward R, Giles JP, Jacobs AM. Experimental transmission and trials of passive-active immunity in viral hepatitis. AMA J Dis Child 1957;94: $409-11$.

16. Hornblum AM, Newman JL, Dober GJ. Against their will: the secret history of medical experimentation in children in Cold War America. New York: Palgrave Macmillan; 2013.

17. Lawson KL, Carlson K, Shynkaruk JM. The portrayal of Down syndrome in prenatal screening information pamphlets. J Obstet Gynaecol Can 2012; $34: 760-8$.

18. Hippman C, Inglis A, Austin J. What is a "balanced" description? Insight from parents of individuals with Down syndrome. J Genet Couns 2012;21:35-44.

19. Bauer PE. Reaching across the disability divide: the case for collaboration with the disability community to construct a robust informed consent process around prenatal screening and diagnosis. Am J Med Genet A 2011;155A:1788-90.

20. Strauss D, Shavelle R, Baumeister A, Anderson T. Mortality in persons with developmental disabilities after transfer into community care. Am J Ment Retard 1998;102:569-81.

21. Strauss D, Kastner TA, Shavelle R. Mortality of adults with developmental disabilities living in California institutions and community care, 1985-1994. Ment Retard 1998;36:360-71.

22. Ohio Developmental Disabilities Council, funder; Tyler CV, director. Optimizing the Primary care of individuals with intellectual and other developmental disabilities: everyone is important! DVD. Cleveland $(\mathrm{OH})$ : Cleveland Clinic; 2011.

23. Westfall JM, VanVorst RF, Main DS, Herbert C. Community-based participatory research in practice-based research networks. Ann Fam Med 2006; $4: 8-14$. 
24. Knapp JR, Smith BR, Sprinkle TA. Clarifying the relational ties of organizational belonging: understanding the roles of perceived insider status, psychological ownership, and organizational identification. J Leadersh Organ Stud 2014;21:273-85.

25. Getrich CM, Sussman AL, Campbell-Voytal K, et al. Cultivating a cycle of trust with diverse communities in practice-based research: a report from PRIME Net. Ann Fam Med 2013;11:550-8.

26. Likumahuwa S, Song H, Singal R, et al. Building research infrastructure in community health centers: a Community Health Applied Research Network (CHARN) report. J Am Board Fam Med 2013;26: 579-87.

27. DeHaven MJ, Gimpel N. Reaching out to those in need: the case for community health science. J Am Board Fam Med 2007;20:527-32.

28. LA Net Community Health Resource Network [homepage]. Available from: http://www.lanetpbrn. net. Accessed July 9, 2014.

29. Williamson AA, Knox L, Guerra NG, Williams KR. A pilot randomized trial of community-based parent training for immigrant Latina mothers. Am J Community Psychol 2014;53:47-59.

30. Knox LM, Aspy CB. Quality improvement as a tool for translating evidence based interventions into practice: what the youth violence prevention community can learn from healthcare. Am J Community Psychol 2011;48:56-64.
31. Guerra NG, Knox L. How culture impacts the dissemination and implementation of innovation: a case study of the Families and Schools Together program (FAST) for preventing violence with immigrant Latino youth. Am J Community Psychol 2008;41:304-13.

32. Knox L, Hahn RG, Lane C. A comparison of unsedated colonoscopy and flexible sigmoidoscopy in the family medicine setting: an LA Net study. J Am Board Fam Med 2007;20:444-50.

33. Forbat L, McCann L. Adults with intellectual disabilities affected by cancer: critical challenges for the involvement agenda. Eur J Cancer Care (Engl) 2010; 19:91-7.

34. Clark LI, O'Toole MS. Intellectual impairment and sexual health: information needs. Br J Nurs 2007;16: 154-6.

35. Walmsley J. Involving users with learning difficulties in health improvement: lessons from inclusive learning disability research. Nurs Inq 2004;11:54-64.

36. Tuffrey-Wijne I. The palliative care needs of people with intellectual disabilities: a literature review. Palliat Med 2003;17:55-62.

37. Janicki MP, Dalton AJ, Henderson CM, Davidson PW. Mortality and morbidity among older adults with intellectual disability: health services considerations. DisabilRehabil 1999; 21:284-94.

38. Nutting PA, Beasley JW, Werner JW. Practicebased research networks answer primary care questions. JAMA 1999;281:686-8. 